Celebrating 50 years of the Primate Society of Great Britain

1. Introduction

The Primate Society of Great Britain was established in 1967 by John Napier and colleagues for the scientific study of everything related to primates. It is credit to Napier's foresight that the Society's $400+$ members represent fields as diverse as anatomy, behaviour, cognition, conservation, ecology, evolution, physiology, neuro- and veterinary sciences and captive welfare. The $50^{\text {th }}$ anniversary conference was held at the Royal Geographical Society, London, on $28^{\text {th }}-29^{\text {th }}$ November 2017. What more prestigious way to start a $50^{\text {th }}$ celebration than with a letter of congratulations from the Queen, HRH Elizabeth II? This was read out as part of the President's opening address by Simon Bearder to the 400 delegates gathered to celebrate past achievements and look forward to the next 50 years of primatology research in the UK.

2. Conservation: big challenges and the 'Top 25' most endangered The first day's theme was conservation threats and solutions, and represented all major taxonomic groups across geographical ranges. The keynote address given by Jane Goodall, DBE, UN peace Messenger, began with a rendition of primate calls (Fig 1). As a pioneer of the study of wild chimpanzees, Goodall spoke of her work to habituate Gombe's chimpanzees before being accepted by 'David Greybeard'. Goodall's discoveries, most significantly tool use by chimpanzees, revolutionized the field of ethology and challenged tenets of human uniqueness. Goodall dates her transition from researcher to campaigner to the 1986 'Understanding Chimpanzees' conference in Chicago. Since then her focus has been on education and conservation, and the work of the Jane Goodall Institute combines human health, education and micro-finance with its conservation aims.

Susan Cheyne (Oxford Brookes U) and Helen Chatterjee (University College London) discussed gibbons, the smallest apes. Cheyne's research on their behaviour and socio-ecology in Indonesia's peat-swamp forest is combined with practical conservation action, damming illegal drainage ditches to 'keep peat wet' and halt the forests' destruction. Chatterjee highlighted gibbons as an urgent conservation cause, reflecting on decreasing population sizes, and demonstrating the value of species distribution modelling - combining data from the fossil record, habitat use and climate change past, present and future - for targeted conservation planning. lan Redmond (Ape Alliance) rounded off the morning session asking whether primates are 'too cute for their own good?'. He hypothesised that it is their cuteness and playfulness that makes primates a target for the pet trade through increasing their owners' perceived charisma. He suggested virtual tourism (e.g. 
http://www.vecotourism.org/ ) as an alternative means to increase awareness of, and connection with, primates.

The afternoon session began with two talks on engagement and education, highlighting the importance for researchers to understand the needs of local populations. Inspired by Alison Jolly's 'Ako the Aye-aye' series, Anna Nekaris (Oxford Brookes U) explained how she and her team examined reactions to the different ways children's books convey conservation messages. They found children responded best to an 'ecophilic' approach where positive imagery helped develop empathy for the animals in the book. Incoming Society President Jo Setchell (Durham U) reminded us of the importance of ethnographic data in conservation, asking whether it might not be more important to learn about human than animal behaviour in order to conserve endangered species successfully. Setchell illustrated the ethnographic approach with examples where local people and researchers have conserved primate populations through mutually beneficial solutions.

Adrian Barnett (National Institute of Amazonian Research) presented a history of neotropical primate conservation, reminding us that large areas remain unsurveyed, and wetted our appetites with the promise of a new primate species. Jörg Ganzhorn (U Hamburg) explained how lemur populations can be driven to tipping points, where seemingly small changes in climate or vegetation can have large effects on populations. Conservation initiatives with immediate pay-offs for local populations must be found, Ganzhorn concluded, acknowledging solutions may include rapid reforestation via fast-growing exotics rather than native species. John Oates (CUNY) was awarded the PSGB Conservation medal for his work with African primates. Accepting his prize Oates acknowledged the work of Ardith Eudey (1925 - 2015) and explained 'conservation is about hanging onto things of wonder in our world'.

The day's academic program concluded with a presentation on the future of primate conservation by Russ Mittermeier (Conservation International, USA) and the launch of 'The World's Top 25 Most Endangered Primates' (Schwitzer et al, 2017), a biennial publication from the Primate Specialist Group of the International Union for the Conservation of Nature (IUCN), the International Primatological Society (IPS), Global Wildlife Conservation, and Bristol Zoological Society. To achieve conservation outcomes, Mittermeier highlighted the need to build capacity, networks and organisation in primate host countries (92 in total), focusing efforts on the most species rich (Brazil, Madagascar, Indonesia and DRC host $57 \%$ of primate species). In particular researchers need to survey, fast-track data processing, and ensure action plans are well-executed. Before distributing 
copies of the 'Top 25', Schwitzer (Bristol Zoological Society) explained the publication is a tool to highlight flagship species across habitat countries. If based solely on surviving numbers of individuals, Schwitzer told us, the list would be mostly gibbons.

3. Past Presidents: Research, conservation and welfare

Day two began with a keynote address from Frans de Waal (Emory $U$ ) on the myth of human cooperation as a 'huge anomaly'. As de Waal demonstrated, we are not the only species to cooperate or demonstrate empathy. Examples included in-group bias in yawn contagion, the influence of early life experience on the development of consolation behaviour, prosocial choice tests, 'fairness' in capuchins, ultimatum games, and work on cortisol and oxytocin as potential mechanisms for emotional contagion.

The rest of the day was largely presented by, and dedicated to, the work of the Society's past Presidents (Fig 2), as well as offering younger members a turn on the stage during a fast-fire poster session. Bob Martin (Field Museum) presented the case for Darwinian medicine. Focusing on reproductive biology, Martin raised as many questions as he answered: why so many sperm? (over 250 million, and not all for sperm competition); is it possible the womb may store sperm? (the human mid-cycle 'window of fertility' is an illusion and actually starts around day 8, not 14); why does the mother not reject the fetus as a foreign body? (genes have been recruited from retroviruses that evolved to circumvent the mother's immunological defences). In summarizing, Martin suggested humans are a 'special case', but it is only through understanding the shared general principles, in light of human epidemiological evidence, that we can understand just how special a case we are.

Ann MacLarnon (Durham U) acknowledged the pioneering work of PSGB members in the 1970s and 1980s in developing non-invasive methods of measuring hormones, and convinced us that there is still much to be learnt about primate environmental adaptability from feces. MacLarnon discussed recent work developing an assay for thyroid hormone (T3) levels in Barbary macaques, mapping potentially adaptive energetic flexibility in response to seasonality, and that on baboons which revealed intricate links between reproductive and stress hormones and anthropogenic factors. As immunoassay techniques continue to evolve, so too will the questions and answers obtained from the humble fecal stool. 
David Chivers (U Cambridge) recapped his career in 'Gibbons, guts and conservation'. Noting important contributions and collaborations from the likes of Clarence Carpenter, Robert Hinde, John Corner, John and Prue Napier, and William Osman Hill, Chivers's early work (1960s) in the Malay Peninsula defined the primate community's needs of space and food. This developed into a focus on the role of seed dispersers in forest regeneration, and later establishing the relationship between diet and gut structure across mammals placing primates in a frugivore 'cluster'.

Bernard Wood (George Washington $U$ ) asked whether we have a realistic perspective on human evolution, and how many hominin taxa should be recognized? In reviewing the evidence for hominin diversity from 7 mya to the present, he described the difficulty and potential circularity in identifying which anatomical features are taxonomically valent and to what extent should they differ? Continuing the morphology theme, Sarah Elton (Durham $U$ ) explored the evolution, biogeography and ecology of Old World monkeys, revealing greater variation in fossil and extant Cercopithecidae morphology than previously recognized. Key to understanding this variation is to identify changes in geographical distribution over time since changes in morphology may represent functional adaptions in response to environmental change, secondary changes following shift in body size, drift or hybridization. Elton concluded that combining methods to quantify form and ecology in modern primates with similar information from the fossil record and spatiotemporal distribution will reveal not just evolutionary patterns, but the processes underlying them.

Robert Barton (Durham U) gave the first of several talks on primate brains and sociality. In 'Brains growing on the tree of life' Barton described how developments in technology and techniques have allowed increasingly detailed examination of primate brain anatomy and evolution, producing a more complex and nuanced picture. Noting that primates have evolved species-specific sensorymotor adaptations with associated forms of embodied cognition, Barton discussed the role of cerebellum expansion and warned against attempts to apply single-factor hypotheses to this complex topic, concluding there is much to be done to understand which structural changes occurred when and under what selection pressures.

Robin Dunbar (U Oxford) asked 'what is so social about primate sociality?' and took the audience through the evidence for the social brain as a phenomenon that is (almost) unique to the primate order. Primates solve ecological problems socially which relies on forming strong (non-reproductive) alliances based on grooming, whilst also keeping track of third-party relationships, and repairing relationships where needed. Dunbar's wide-reaching work incorporating data from a range of 
human contexts including social media usage is compelling evidence that, for some species at least, sociality is a driver for brain evolution.

Phyllis Lee (U Stirling) asked 'are primates special?', and looking back over the preceding talks, took us through the 'yes - no' answers. Primates represent a diverse radiation with significant behavioural and morphological variation, but no more so than birds; they are threatened by human activity and are of huge conservation concern, but no more so than other groups; their large brains, sociality and life-history strategies are peculiar, but are only unique in their relationship to the evolution of humans. Concluding, Lee concurred that 50 years of a Society dedicated to all aspects of 'primates' suggests there is something special about them, even if it is simply that they are lots of fun to study.

Hannah Buchanan-Smith (U Stirling) gave the conference's final talk, 'Welfare of primates: why should we care?'. It brought to the fore an implicit message featured in many of the previous talks, that increasingly primates live in environments where their welfare is dependent on human actions: whether that be human activity encroaching on their habitat, or in zoos, breeding colonies, or sanctuaries. Buchanan-Smith acknowledged the pioneering work of Hilary Box (President from 19931998) and reviewed an impressive body of work relating to primate welfare. Examples included changes in policy and legislation resulting from an increased understanding of primates' cognitive and emotional capacities and behavioural needs. Buchanan-Smith discussed innovative approaches to improving primate welfare from novel methods and technologies to initiatives such as the UK's National Centre for the Replacement, Refinement and Reduction of animals in Research (NC3Rs) which, through focusing on quality of science, has improved standards of primate welfare in research.

\section{The next 50 years}

This stimulating and highly enjoyable conference brought together primatologists from 27 countries around the globe. New technologies were prominent, but key messages largely have not changed: many primates face extinction; key threats are habitat destruction, bushmeat trade, disease, and climate change; gibbons are the most threatened group; we need more data to inform and effectively execute conservation efforts; we must raise the profile of these causes. Discussions abounded, for example delegates considered the need to think before sharing images of primates on social media - selfies and images of primates in close contact with humans can be taken out of context and inadvertently promote primates as pets or photo props. The key message from the 400 
delegates themselves was that the Primate Society of Great Britain is in excellent health and set for a vibrant and productive next 50 years.

Conference programme with abstracts and past Presidents' memoirs can be found in the PSGB's journal Primate Eye (2017) vol. 123 (Oct), pp6-61.

Schwitzer, C., Mittermeier, R.A., Rylands, A.B., Chiozza, F., Williamson, E.A., Macfie, E.J., Wallis, J. and Cotton, A. (eds.). 2017. Primates in Peril: The World's 25 Most Endangered Primates 2016-2018. IUCN SSC Primate Specialist Group (PSG), International Primatological Society (IPS), Conservation International (Cl), and Bristol Zoological Society, Arlington, VA. 99 pp.

Emily J. Bethell ${ }^{1}$, Lewis Dean², Andrew Smith ${ }^{3}$, Simon K. Bearder ${ }^{4}$

${ }^{1}$ Centre for Research in Brain and Behaviour, Liverpool John Moores University, Liverpool

${ }^{2}$ General Secretary, Primate Society of Great Britain

${ }^{3}$ Department of Biology, Anglia Ruskin University, Cambridge

${ }^{4}$ Nocturnal Primate research Group, Dept. Anthropology, Oxford Brookes University, Oxford Email E.J.Bethell@ljmu.ac.uk 